\title{
Investigation of the Role of Polar Vortex in Iranian First and Last Snowfalls
}

\author{
Abdolreza Kashki ${ }^{1} \&$ Javad Khoshhal $^{1}$ \\ ${ }^{1}$ Department of Physical Geography, Faculty of Planning and Geography Sciences, University of Isfahan, \\ Isfahan, Iran \\ Correspondence: Abdolreza Kashki, Department of Physical Geography, Faculty of Planning and Geography \\ Sciences, University of Isfahan, Isfahan, Iran. Tel: 98-915-173-1453. E-mail: r.kashki@yahoo.com
}

Received: July 4, 2013 Accepted: August 27, 2013 Online Published: November 22, 2013

doi:10.5539/jgg.v5n4p161 URL: http://dx.doi.org/10.5539/jgg.v5n4p161

\begin{abstract}
From a climatological point of view, a winter day usually is symbolized with cold weather or a snowfall day. The first and last days of snowfall may be considered as winters' real starting and finishing points. Starting and finishing points of seasons are affected by sun location, which is fixed yearly whereas snowfalls usually begin with cooling and they may happen in any time. Cooling has several reasons, the most important of which may be approaching and locating of polar vortex trough or isolated cut-off low systems from polar vortex on a region. The current research aims at identifying the role of polar vortex in creating cooling necessary for Iranian first and last snowfalls and finding a way for estimating its occurrence time. Firstly, snowfall data of all synoptic stations is collected from Islamic Republic of Iran Meteorological Organization (IRIMO) in 3-hourly basis. After statistical review, snowfall data related to 38 stations which have at least 33 years continuous statistics from 1976 to 2008 is considered proper in order to be used in the research. Then, after determining cold and warm peak times in summers and winters and basing them, the first and last days occur snowfall after warm and cold peak in each year have been respectively identified first and last snowfalls. The first and last snowfall days (calendar series) changed into Julian days. Using Smada 6.0 software, resulted series have been fitted by different statistical distributions (for example normal, 2 parameter log normal, 3 parameter log normal, pearson type $3, \log$ pearson type 3 and gumball distributions) and most proper distributions have been recognized. Ultimately, using those distributions, occurrence probability of snowfall days has been calculated. Geopotential height data for those selected days is collected from National Center for Environmental Program and National Center for Atmospheric Research (NCEP/NCAR). Using Grads software, related maps have been drawn. Resulted maps have been analyzed through the using of Skew-T Log P diagrams obtained from University of Wyoming. In most of the cases, Iranian first and last snowfall days happen because of cooling resulted from locating of polar vortex troughs or their isolated cut-off low systems on Northwestern of Iran or its neighborhood. Using astrological calendar and getting assistance from probability rules, can be estimate Iranian first and last snowfall occurrence times.
\end{abstract}

Keywords: polar vortex, first snowfall day, last snowfall day, occurrence probability, synoptic analysis, Iran

\section{Introduction}

In the mass media, it has been heard; seen or read expressions such as spring day, summer day and/or winter day so many times. Spring day symbol is a day in which weather is fair and calm and the sky is fairly clear. Summer day symbol is a day in which the sky is completely clear and weather is calm and warm. Also, winter day symbol is a day in which weather is completely cold and/or there is snowfall. From a climatological point of view, spring, summer and/or winter days do not depend on astrological calendar and may happen any time throughout the year. For instance, a spring day may occur in winter or a winter day may happen in summer in terms of astrological calendar. Therefore, a winter day usually is symbolized by a snowfall day although it happens in a summer season with respect to astrological calendar and snowfall quantity and extent seems little.

Snow usually falls from cover clouds, especially Altostratus and Stratonimbus clouds, in sub-zero conditions (Kavyani \& Alijani, 2007), in this way, clouds are formed as a result of frontogenesis or cold advection from cold regions or higher latitudes. Falling cold weather from higher latitudes is made by waves located within polar vortex and their troughs get narrow toward lower latitudes and form fronts on earth surface. In addition to 
the cooling factor, sufficient humidity is necessary for snowfall and the higher the humidity, the higher falling duration and quantity. It is so important to identify cooling factor in snowfall in every region and it could affect snowfall occurrence prediction. Polar vortex is one of the most principal factors of cooling creation for snowfall. Following sun location, it shrinks toward the North in summers and spreads toward the South in winters. The current research attempts at identifying the role of polar vortex in Iranian first and last snowfalls.

The first snowfall day is a day where snow falls after a warm peak in summer and the last snowfall day is a day where snow falls after a cold peak in winter. In every year, it is important to study first and last snowfalls and their interval in the fields including water resources management, agriculture, tourism, winter sports and etc, especially in dry regions. The first snowfall day indicates the beginning of water restoration and the last snowfall day indicates the end of water restoration. The interval between them reveals water restoration or consumption period. Usually, to determine occurrence date of first and last snowfall, $50 \%$ probability is used. $50 \%$ probability means that the first snowfall day happens in that day or its previous days or that day or its next days. When occurrence probability of first and last snowfall day increases, those days get closer to astrological winter and summer seasons and snowfall continuity and extent will increase or decrease respectively.

Synoptic climatology is a science which investigates the relationship between a specified region's atmospheric circulation patterns with surface environment (Masoodian, 2006). One of the most important goals of synoptic and dynamic climatology is better understanding of the effects of atmospheric circulation on surface phenomena (precipitation, air temperature and snow), it is important to identify polar vortex as one of the most important elements of global atmospheric circulation. Any change in polar vortex together with sub-tropical high pressure oscillations determines climatological conditions of middle latitudes (Moradi, 2001).

Polar vortex is a cyclonic planetary scale circulation which is generally located in Polar Regions and exists between middle troposphere and stratosphere (AMS Glossary, 2000). Polar vortex may be considered as a region which has the strongest meridional geopotential height gradient in Northern and Southern hemispheres (Fraunfeld \& Davis, 2003). Studying polar vortex, Burnett (1993) concluded that the position of a polar vortex center and its meridian or zonal state are considered as an important index in evaluating changes in precipitation and hurricane tracks. Rohli and his colleagues (2005) have investigated Northern Hemisphere polar vortex variability in January and its relationship with regional teleconnection phenomena and hemispheric temperature. Their findings show that polar vortex shows no long-term trend with respect to area and geometrical shape. Hejazizadeh (1993) has researched the effects of Sub-tropical high pressure together with polar vortex on seasonal shift in Iran and concluded that any simultaneous change in Sub-tropical high pressure and polar vortex controls climate of Iran. Studying polar vortex using precipitation, monthly earth surface temperature and monthly 500 hpa pressure level in six cold months (October to March) in period from 1971-1989, Moradi (2001) has found that spread precipitation and temperature decline in Iran come with high activity of Icelandic low pressure and has a negative correlation with contour position of polar vortex along with $40^{\circ}$ and $50^{\circ} \mathrm{E}$ longitude. Paknazar (2004) has investigated polar vortex position and its effect on Northeastern of Iran extreme cold in 300 hpa pressure level using monthly mean temperature data in cold months (December, January and February) in synoptic stations of Mashhad, Sabzevar and TorbateHeydariyeh in period from 1986-1977 and found that occurring maximum and minimum temperatures is related to polar vortex's maximum expansion and minimum contraction with one month delay respectively. Alidadi (2010) believes that snowfall days of Iran are related to Northward advancement of Sub-tropical ridge to higher latitudes and as a result, polar vortex exits from its normal state.

The goals of this research are to determine the role of polar vortex in first and last snowfalls of Iran using geopotential height data at $500 \mathrm{hpa}$ level and to predict the first and last snowfall days using different statistical distributions.

\section{Data \& Methodology}

In order to carry out the current research, snowfall day data related to all synoptic stations from their establishment to 2008 is collected from Islamic Republic of Iran Meteorological Organization in 3-hourly basis. Monitoring mentioned data indicates that only 38 synoptic stations have data longer than 33 years (1976-2008 statistic periods). Those stations have been selected for more investigation (Figure 1). 


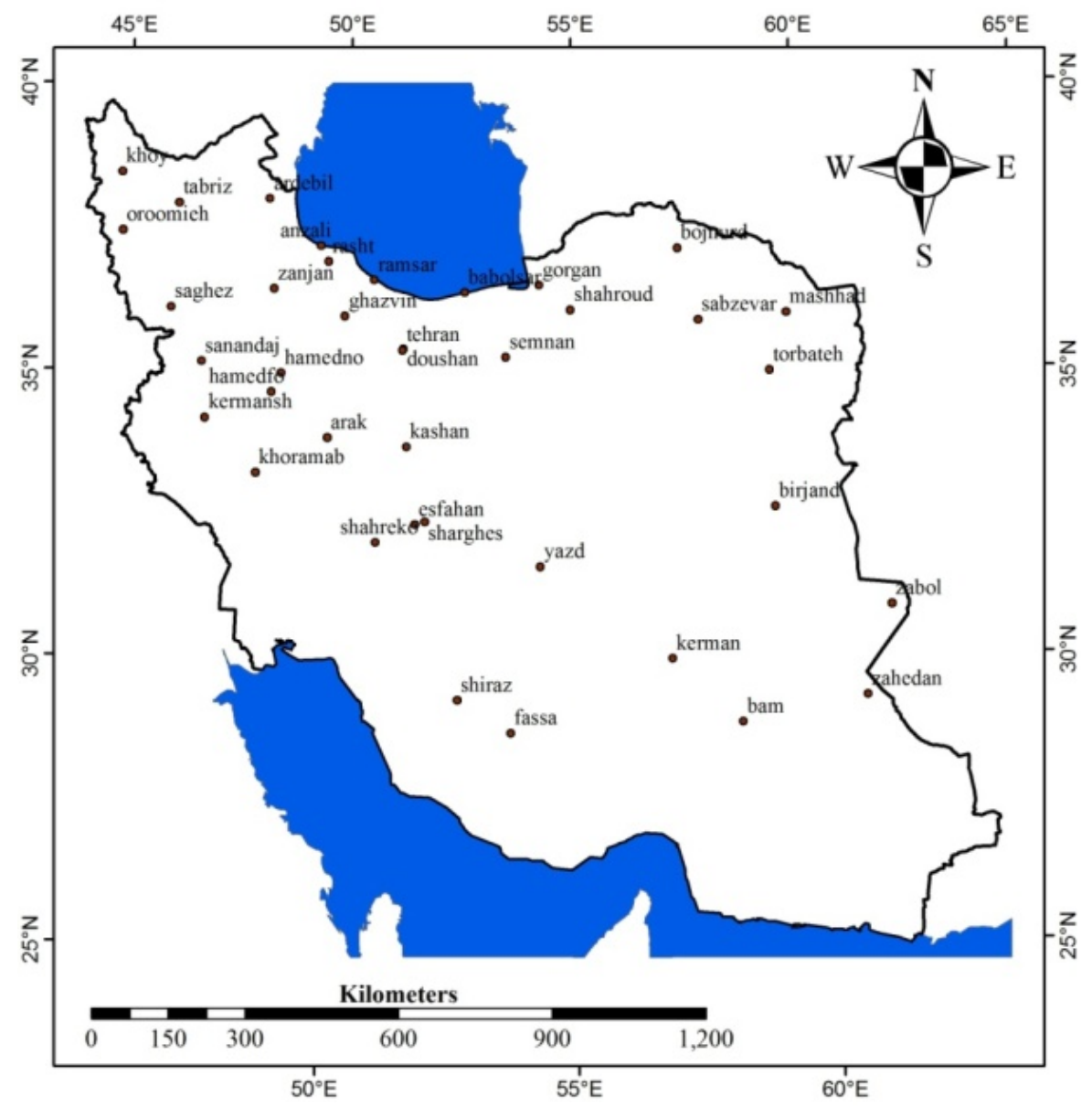

Figure 1. Position of synoptic stations used in this study

Firstly, the average of yearly warmest and coldest days is calculated with respect to temperature of the selected stations. Then, with regard to yearly warmest and coldest days, the dates of first and last snowfall days have been respectively determined per year. After from determining of the first and last snowfall days per year, a calendar series of those days at least one station has reported snowfall has been constructed. Therefore, two calendar series of first and last snowfall days have been obtained. Ultimately, those calendar series have been changed into Julian days and two time series have been achieved. With using Smada6.0 software, different statistical distributions were fitted on the first and last snowfall day data and the best statistical distribution was selected. The Chi Square test for determining whether the data follow a specific probability distribution was computed using below equation (Mahdavi, 2002).

$$
\text { R.S.S }=\left[\sum_{i=1}^{n}\left(Q E_{i}-Q O_{i}\right)^{2} /(n-m)\right]^{0.5}
$$

Where,

R.S.S. $=$ Residual Sum of Squares.

$\mathrm{QEi}=$ Expected data.

QOi $=$ Observational data.

$\mathrm{n}=$ the number of data.

$\mathrm{m}=$ the number of parameters in distributions, for Normal, 2 Parameter Log Normal, Gumbell and Log Gumbell are 2 and Pearson, Log Pearson and 3 Parameter Log Normal are 3.

\section{Discussion and Results}

Minimum quantity of R.S.S. was determined the best fit distribution. The first snowfall day data is compatible 
with probability distribution of Pearson Type 3 and the data for the last snowfall days with probability distribution of Log-Pearson Type3 (table 1).

Table 1. Quantities of R.S.S. for the first and last snowfall days

\begin{tabular}{ccccccc}
\hline $\begin{array}{c}\text { Probability } \\
\text { distributions }\end{array}$ & Normal & $\begin{array}{c}\text { 2Parameter } \\
\text { Log Normal }\end{array}$ & $\begin{array}{c}\text { 3Parameter } \\
\text { Log Normal }\end{array}$ & $\begin{array}{c}\text { Pearson } \\
\text { Type3 }\end{array}$ & $\begin{array}{c}\text { Log Pearson } \\
\text { Type 3 }\end{array}$ & Gumbell \\
\hline $\begin{array}{c}\text { First snowfall days } \\
\text { (R.S.S) }\end{array}$ & 9.71 & 10.28 & 10.46 & 7.63 & 7.84 & 12.26 \\
$\begin{array}{c}\text { Last snowfall days } \\
\text { (R.S.S) }\end{array}$ & 5.43 & 5.21 & 5.26 & 5.37 & 5.15 & 5.52 \\
\hline
\end{tabular}

So, regarding proper distributions, the first and last snowfall days are calculated with different probabilities and return periods per year (Table 2).

Table 2. The first and last snowfall days are calculated with different probabilities and return periods yearly

\begin{tabular}{cccc}
\hline Probability & Return period & First snowfall day & Last snowfall day \\
\hline 99 & 1 & Nov. 14 & Jun. 29 \\
95 & 1.1 & Nov. 13 & Jun. 9 \\
90 & 1.1 & Nov. 13 & May 30 \\
80 & 1.3 & Nov. 12 & May 18 \\
70 & 1.4 & Nov. 10 & May 10 \\
60 & 1.7 & Nov. 8 & May 3 \\
50 & 2 & Nov. 5 & Apr. 27 \\
40 & 2.5 & Nov. 1 & Apr. 21 \\
30 & 3.3 & Oct. 26 & Apr. 15 \\
20 & 5 & Oct. 18 & Apr. 8 \\
10 & 10 & Oct. 3 & Mar. 30 \\
5 & 20 & Sep. 16 & Mar. 23 \\
1 & 100 & Aug. 6 & Mar. 11 \\
\hline
\end{tabular}

Concerning probabilities chosen for snowfall day occurrence, $2.5^{\circ} * 2.5^{\circ}$ daily gridded reanalysis data in 500 hpa level related to National Center for Environmental Program and National Center for Atmospheric Research (NCEP/NCAR) in $0^{\circ}-120^{\circ}$ latitude and $0^{\circ}-90^{\circ}$ longitude domain and atmospheric sounding data related to University of Wyoming for snowfall days has been used. Using Grads software, relevant maps are drawn. Considering drawn maps, the role of polar vortex (cooling factor) is determined for creating snowfall conditions.

According to Frauenfeld and Davis (2003) research, specific isohypse was used to show polar vortex contour in every month in 500 hpa level (Table 3 ), they have studied daily and monthly changes of geopotential height in every 5 meridian gridpoint in order to identify monthly polar vortex contour within baroclinic zone.

Table 3. Geopotential height contours used to define the Northern Hemisphere Circumpolar Vortex

\begin{tabular}{ccccccccccccc}
\hline Month & Jan. & Feb. & Mar. & Apr. & May & Jun. & July & Aug. & Sep. & Oct. & Nov. & Dec. \\
\hline $\begin{array}{c}500 \mathrm{hpa} \\
\text { isohypse }(\mathrm{m})\end{array}$ & 5460 & 5460 & 5520 & 5580 & 5640 & 5700 & 5700 & 5760 & 5640 & 5580 & 5520 & 5460 \\
\hline
\end{tabular}

Source: Frauenfeld and davis (2003).

Also, to identify daily polar vortex, a contour passing the location of the strongest meridional gradient of geopotential height was considered as daily polar vortex (blue-colored). A contour passing from the last synoptic 
station of Iran with respect to latitude at $500 \mathrm{hpa}$ level was considered cut-off line (red-colored).

According to Table 2, it can be told that snowfall occurrence period is shorter than its non-occurrence period. With $50 \%$ probability, Iranian first snowfall happens on November 5 and with $50 \%$ probability, Iranian last snowfall day occurs on April 27. The interval between those two dates is 173 days (snowfall period). If we subtract this period quantity from total days of year (365), snowfall non-occurrence period will be 192 days with $50 \%$ probability.

The statistical investigation of snowfall days in studied statistical period reveals that snowfall first and last days belong to the stations located in Northwestern of Iran including Ardebil, Tabriz, Khoy and etc.

According to Table 2, with $95 \%$ probability, Iranian first snowfall is on November 13 and before it annually and only in 5\% of cases, it may happen after this date. And, with 5\% probability, snowfall takes place September 16 and before it. Therefore, in $90 \%$ of cases, snowfall will happen between those two dates, which this interval is in the fall. Accordingly, with $95 \%$ probability, Iranian last snowfall is on June 9 and before it annually and only in $5 \%$ of cases, it may happen before this date. The interval between those dates is completely compatible with spring.

The investigation of $500 \mathrm{hpa}$ level maps drawn for first and last snowfall days indicates that when polar vortex troughs and its isolated cut-off low get closer to or locates on the Northwestern of Iran, snowfall conditions are formed. In this research, for first and last snowfall days, 3 maps drawn with 5, 50 and 95 percents probabilities are presented (case examples).

\subsection{Synoptic Analysis of Maps of First Snowfall Days}

With $5 \%$ probability, Iranian first snowfall day is on September 16 and before it. In Figure 2, the map of circulation pattern is presented for 15 September 2006. As one can see in this map, the end of one trough has located on the Northwestern of Iran, which does not have much depth. On this day, Khoy station has reported snowfall. On the mentioned day, monthly polar vortex is in green, the strongest meridional gradient of geopotential height showing daily vortex is in blue and contour in red shows cut-off line indicating snowfall in upper parts (higher latitudes). On this day, atmospheric sounding data is not available in the neighborhood stations in order to draw Skew-T Log P diagram.

Figure 3 indicates circulation pattern of 5 November 1981. As may be seen in Table 2, first snowfall day happens on that day or before it. On this day, Khoy, Tabriz, Zanjan have reported snowfall. As one can see in this map, polar vortex trough has completely located on the Northwestern of Iran and daily vortex and cu-off line are drawn so close to and compatible with it. In Figures 4 and 5, Skew-T Log P diagram is drawn for 4 and 5 November 1981 on 12 and 00 GMT hours respectively in Yerevan station located in Armenia. As these diagrams show, conditions are completely ready for snowfall. It is worthy to note that atmospheric sounding data is not available in any station closer than this station to the Northwestern of Iran.

Circulation pattern map of 13 November 1993 is shown in Figure 6. As mentioned, Iranian first snowfall happens in that day or before it with $95 \%$ probability. As one can see in that map, cut-off low system isolated from polar vortex trough has located on the Northwestern of Iran. On the mentioned day, Ardebil, Khoy, Tabriz, Qazvin, Hamedan, Saqqez and Zanjan stations have reported snowfall. In Figure 7, Skew-T Log P on 12 GMT of that day in Kermanshah station has been shown. As one can see in diagram, instability conditions have occurred in mentioned day.

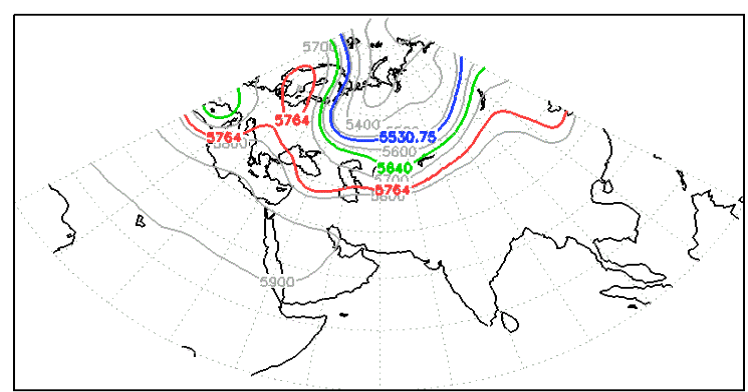

Figure 2. 500 hpa daily mean geopotential height map for 15 September 2006

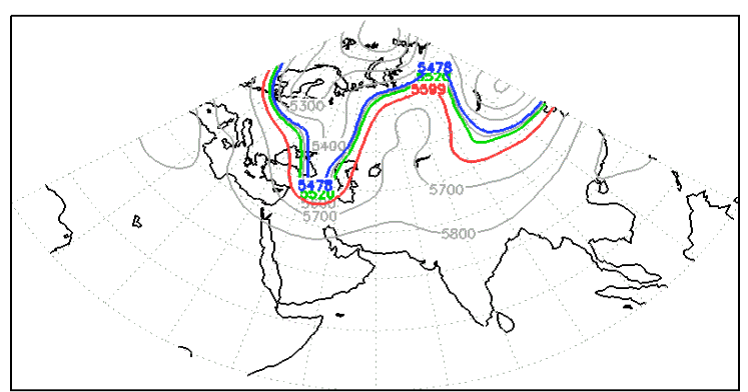

Figure 3. 500 hpa daily mean geopotential height map for 5 November 1981 


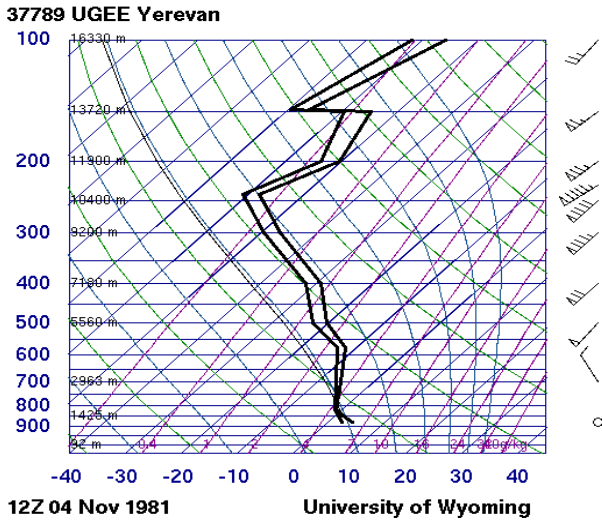

Figure 4. SKEW-T diagram for 12z, 4 November 1981 in Yerevan station

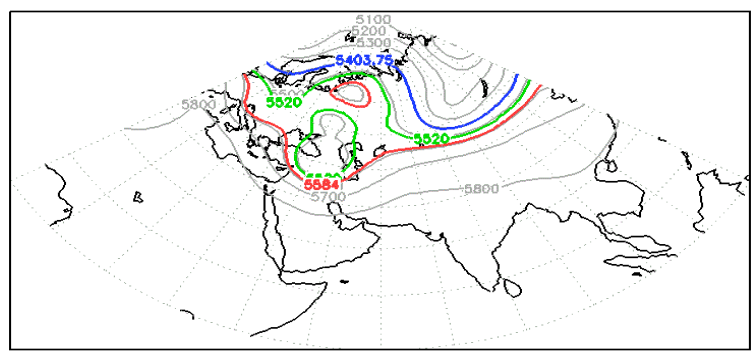

Figure 6.500 hpa daily mean geopotential height map for 13 November 1993

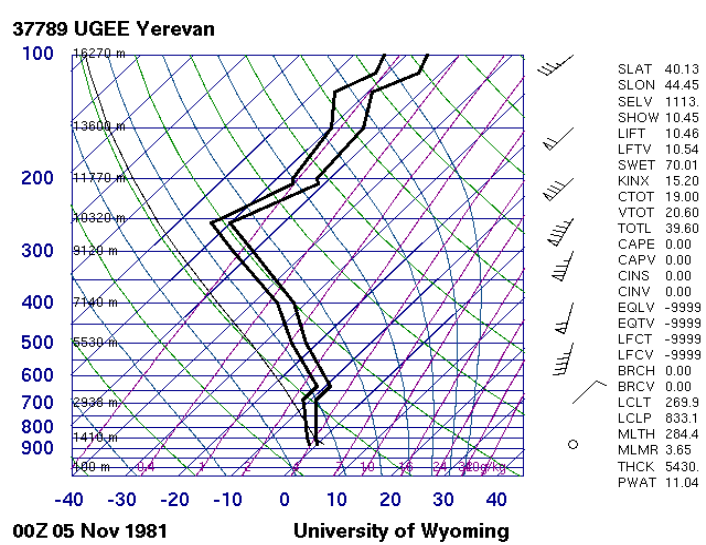

Figure 5. SKEW-T diagram for 00z, 5 November 1981 in Yerevan station

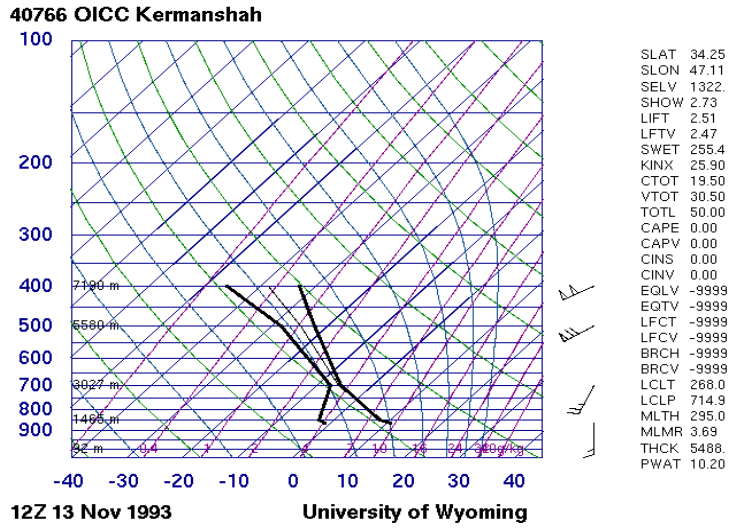

Figure 7. SKEW-T diagram for $12 \mathrm{z}, 13$ November 1993 in Kermanshah station

\subsection{Synoptic Analysis of Maps of Last Snowfall Days}

With 5\% probability, Iranian last snowfall happens on 23 March or before it. Figure 8, shows 500 hpa circulation pattern map for 23 March 1992. As one can see in that map, polar vortex trough has located on the Northwestern of Iran and its end extends down to Midwest of Iran. On that day, 14 stations located in Western and Northwestern of Iran have reported snowfall. In Figure 9, Skew-T Log P diagram of that day for 00 GMT in Kermanshah station has been shown. As one may see in that diagram, in $850 \mathrm{hpa}$ level, dew point and air temperature lines have join together, showing instability in this level.

In Figure 10, circulation pattern map has been presented for 27 April 1979. With 50\% probability, Iranian last snowfall happens in that day or before it in the year. On that day, Ardebil station has reported snowfall again. As may be seen in that map, the end of trough lagged behind polar vortex has located on the Northwestern of Iran. On this day, atmospheric sounding data is not available in neighborhood stations in order to draw Skew-T Log P diagram.

The map of circulation pattern has been drawn in Figure 11 on 2 June 1978. On that day, Ardebil station has reported snowfall. It is worthy to note that the last snowfall day with $95 \%$ probability will be 9 June and before it. Because there has been no snowfall on 9 June, to present a sample of this probability, 2 June has been presented. As one may see in this map, the trough resulted from polar vortex has extend down in Western of Iran toward South. Because humidity is low due to warm weather, only Ardebil station, the coldest location in this season, has reported snowfall, which is probably little. On that day, there is not data for drawing Skew-T Log P. Therefore, 00 GMT diagram of 1 June 1978 related to Yerevan station has been presented (Figure 12). This diagram confirms instability in neighborhood stations the day before snowfall occurrence. 


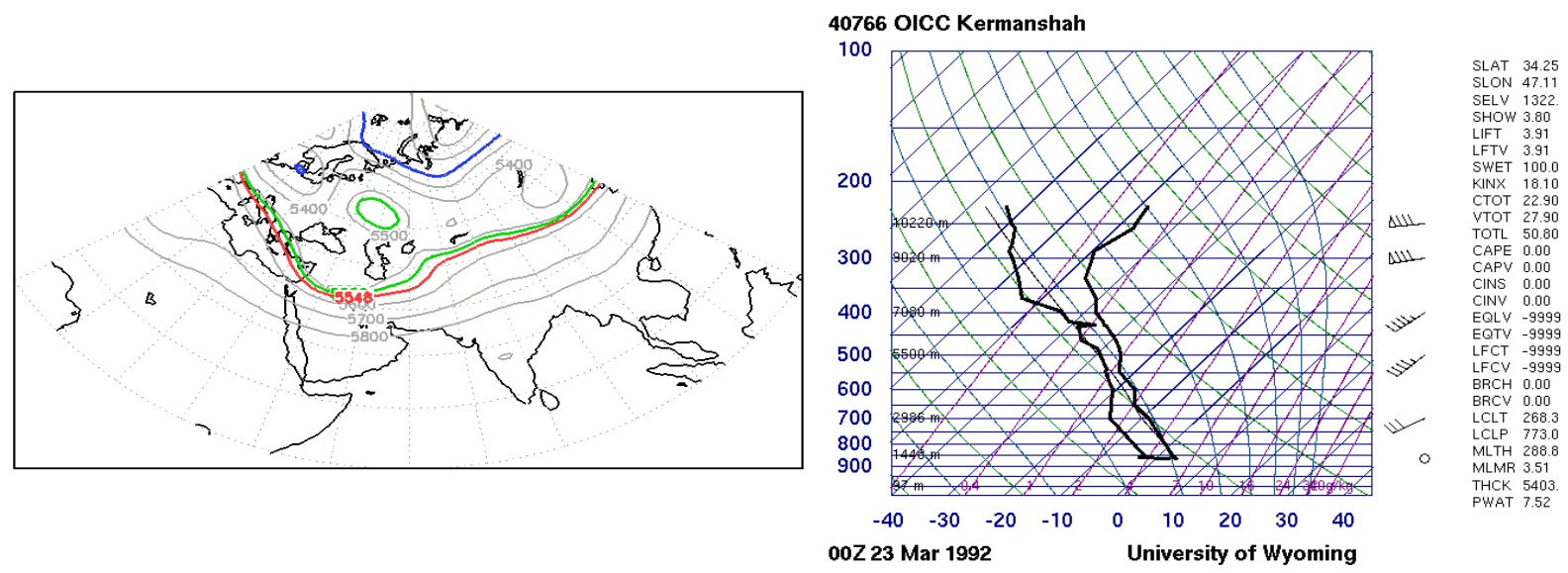

Figure 8.500 hpa daily mean geopotential height map for 23 Mars 1992

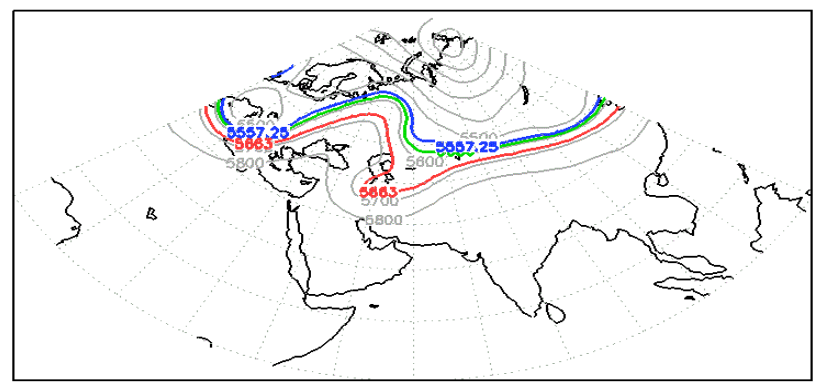

Figure 10. 500 hpa daily mean geopotential height map for 27 April 1979
Figure 9. SKEW-T diagram for 00z, 23 Mars 1992 in Kermanshah station

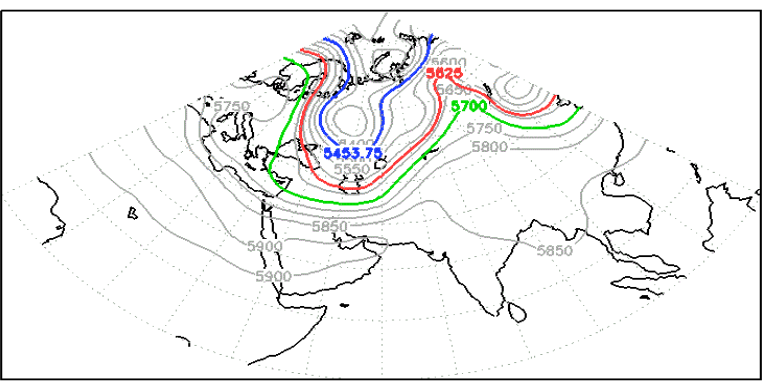

Figure 11.500 hpa daily mean geopotential height map for 2 June 1978

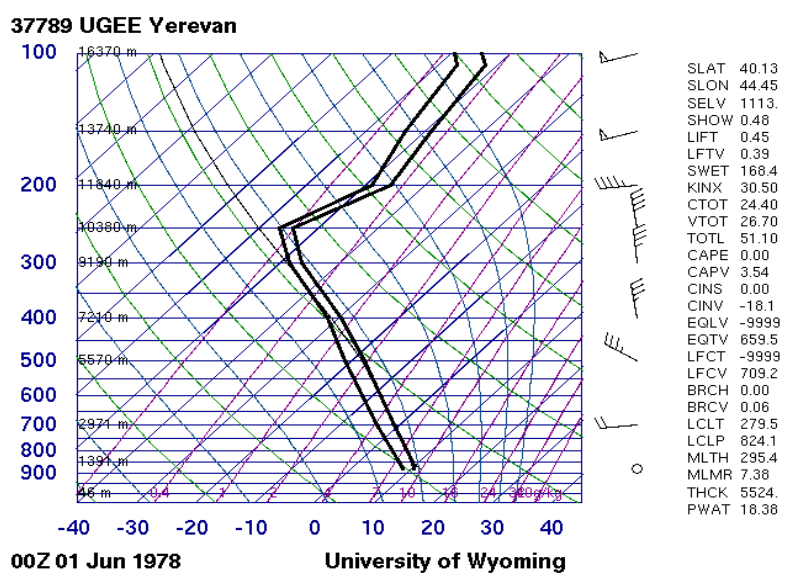

Figure 12. SKEW-T diagram for 00z, 1 June 1978 in Yerevan station

\section{Conclusions}

According to astrological calendar and by means of probability rules, Iranian first and last days of snowfall can be estimated with high accuracy. While polar vortex moves toward the South and locates on Northwestern of Iran, snowfall starts in the fall and when it moves backward to the North, snowfall finishes in the spring from the North.

Summary of findings:

(1). The length of snowfall period is shorter than its non-snowfall period in Iran. 
(2). First snowfalls start from the Northwestern of Iran and last snowfalls finishes in the Northwestern of Iran.

(3). With $90 \%$ probability, First and last snowfalls occur in the fall and spring respectively and $10 \%$ of them happen in other seasons.

(4). Iranian first and last snowfalls happen because polar vortex troughs or their isolated cut-off low systems near to or locate on Northwestern of Iran.

(5). The higher the humidity of the atmosphere, the more the effect of cooling resulted from locating of polar vortex or its isolated cut-off low system and the higher the continuity and intensity of the snowfall.

(6). The closer the first and last days of snowfall to the warm period of the year, the lower snowfall extent and continuity.

The main problem of this research is statistical inconsistency in the synoptic stations of Iran, so it is used from long-term synoptic stations (1976-2008 periods).

An important consideration for future work is predicting the first and last snowfalls with polar vortex characteristics. It is the goal of our ongoing research to address this issue.

\section{References}

Alidadi, M. (2010). The role of polar vortex on determination of kind and quantity of precipitation in Mid-West of Iran (master thesis). Geography and Urban Planning, University of Tehran.

American Meteorological Society Glossary Home Page. Retrieved from http://glossary.ametsoc.org/wiki/Main-Page

Burnett, A. W. (1993). Size variations and long-wave circulation within the January Northern Hemisphere $\begin{array}{lllll}\text { circumpolar } \quad \text { vortex. } & \text { Journal } & \text { of } & \text { Climate, } & 614-1920 .\end{array}$ http://dx.doi.org/10.1175/1520-0442(1993)006<1914:SVALWC >2.0.CO;2

Frauenfeld, O. W., \& Davis, R. E. (2003). Northern Hemisphere circumpolar vortex trends and climate change implications. Journal of geophysical research, 108(D14), 4423. http://dx.doi.org/10.1029/2002JD002958

Hejazizadeh, Z. (1993). Investigation of sub tropical high pressure variations on season shift in Iran (PhD thesis). Physical Geography, Tarbiat Modarres University.

Kavyani, M. R., \& Alijani, B. (2007). The foundations of climatology (12th Ed.). Tehran: Samt Publication.

Mahdavi, M. (2002). Applied Hydrology (2nd Ed.). Tehran: University of Tehran Publication.

Moradi, H. R. (2001). Synoptic analysis of polar vortex and effects on climate of Iran (PhD thesis). Geography and Environmental Planning, Tarbiat Modarres University.

National Center for Environmental Program and National Center for Atmospheric Research Home Page. Retrieved from http://www.esrl.noaa.gov/psd/data/gridded/data.ncep.reanalysis.pressure.html

Paknazar, S. (2004). Investigation of polar vortex position and effect on severe cold in northeast of Iran (MA) Meteorology, Islamic Azad University of North of Tehran.

Rohli, R. V., Wrona, K. M., \& Mchugh, M. J. (2005). January northern hemisphere circumpolar vortex variability and its relationship with hemispheric temperature and regional teleconnection. Int. J. Climatol, 25, 1421-1436. http://dx.doi.org/10.1002/joc.1204

University of Wyoming Home Page. Retrieved from http://weather.uwyo.edu/upperair/sounding.html

Yarnal, B., Translate by Masoodian, S. A. (2006). Synoptic climatology in environmental studies (1st Ed.). Isfahan: University of Isfahan Publication.

\section{Copyrights}

Copyright for this article is retained by the author(s), with first publication rights granted to the journal.

This is an open-access article distributed under the terms and conditions of the Creative Commons Attribution license (http://creativecommons.org/licenses/by/3.0/). 